\title{
In vivo immunological toxicity in mice of carbon nanotubes with impurities
}

\author{
Shozo Koyama ${ }^{1} *$, Yoon Ahm Kim ${ }^{2}$, Takuya Hayashi ${ }^{2}$, Kenji Takeuchi ${ }^{2}$, Chifumi Fujii ${ }^{1}$, \\ Naomi Kuroiwa ${ }^{1}$, Haruhide Koyama ${ }^{1}$, Tamotsu Tukahara ${ }^{1}$, Morinobu Endo ${ }^{2, *}$ \\ ${ }^{1}$ School of Medicine, Shinshu University, 3-1-1 Asahi, Matsumoto 390-8621, Japan \\ ${ }^{2}$ Faculty of Engineering, Shinshu University, 4-17-1 Wakasato, Nagano 380-8553, \\ Japan
}

\begin{abstract}
The longstanding question as to whether carbon nanotubes are intrinsically toxic hinders their widespread industrial application. Here, we clarify the effect of impurities within such tubes through systemic studies of immunological responses in mice by monitoring and examining changes in peripheral T-cell subset and peripheral cytokine levels and histology. Contaminated and clean tubes were subcutaneously implanted in mice. The implanted tubes with impurities clearly induced immunological toxicity and localized alopecia, whereas extremely pure implanted tubes showed good biocompatibility. Our studies suggest that such high-temperature thermal treatment is an effective way to improve the biocompatibility of carbon nanotube.
\end{abstract}

* Corresponding author: Tel: +81-263-35-2598: Fax: +81-263-36-3644; E-mail: skoyama@shinshu-u.ac.jp (S. Koyama); Tel: +81-26-269-5201: Fax: +81-26-269-5208; E-mail: endo@endomoribu.shinshu-u.ac.jp (M. Endo) 


\section{Introduction}

One-dimensional carbon nanotubes [1] are at the leading edge of the rapidly developing field of nanotechnology. Their unique size-dependent properties make them useful in many areas of human life [2]. Currently, one critical social factor limiting the industrial applications of carbon nanotubes [3] is the suspected, although controversial, toxicological results published relating to their use [4-8]. However, it remains to be determined which properties of carbon nanotubes (i.e., size, shape, aspect ratio, surface properties and impurities) directly contribute to the toxicity in mice implanted with such nanotubes. For example, carbon nanotubes are easily contaminated by disordered carbon, metallic impurities and polycyclic aromatic hydrocarbons (PAHs) during growth, by functional groups and defects during purification, and by dispersant agents during their administration in solution form; such impurities might have led to a misunderstanding of the intrinsic toxic nature of carbon nanotubes. Thus, an appropriate route for preparing highly pure, chemically inert, crystalline carbon nanotubes should be developed to avoid the effect of impurities within them. In addition, a reliable protocol for the direct comparative evaluation of the toxicities of a variety of carbon nanotubes should also be developed; currently there is as yet no such protocol owing to the poor understanding of the toxicological mechanisms of in vitro and in vivo responses associated with carbon nanotube implantation.

With the above background, it is necessary to evaluate the intrinsic toxic nature of carbon nanotubes using a reproducible and reliable protocol [7], because impurities including catalyst particles within the tubes have been suggested to serve as a catalyst for oxidative stress [9-13]. Therefore, to determine whether impurities within the tubes lead to acute toxicity and up to what extent this toxicity depends on the amount of 
impurities, we controlled the remaining amount and types of impurities within the tubes by thermally treating highly contaminated as-grown tubes at 1800 and $2800^{\circ} \mathrm{C}$ in argon. Then we examined the immunological responses of subcutaneously implanted mice by monitoring in detail the changes in peripheral T-cell subset and peripheral cytokine levels and histology. We found that the origins of the toxicities acquired from the as-grown and the thermally treated tubes at $1800^{\circ} \mathrm{C}$ are different. For the as-grown tubes, the disordered carbon including defects, PAHs, and functional groups give rise to acute toxicity, whereas for the tubes thermally treated at $1800^{\circ} \mathrm{C}$, a small amount of exposed iron on the outer surface of the tubes is oxidized rapidly to form water-insoluble ferric ions which induce toxicity. Extremely clean tubes, prepared at high-temperature thermal treatment of $2800^{\circ} \mathrm{C}$ are shown to have excellent biocompatibility in this assay.

\section{Experimental}

\subsection{Production of MWCNTs}

In this study, carbon nanotubes were synthesized in a vertical tubular reactor, the so-called floating reactant method $[14,15]$, using an organic-metallic compound (e.g., ferrocene) as a catalyst precursor, toluene as a carbon feedstock and hydrogen as a carrier gas in a semi-continuous system. Benzene solution containing an organic-metallic compound was fed into the reactor using a micro-feeding pump. The reaction temperature is approximately $1200^{\circ} \mathrm{C}$. The following thermal treatment of nanotubes was carried out at 1800 and $2800^{\circ} \mathrm{C}$ for 30 min using a graphite resistance furnace operating at a high purity.

\subsection{Animals, surgical implantation and sampling}

One hundred twenty female BALB/c mice, aged 5 weeks, were purchased from 
SLC (Japan). All the animals were maintained and bred in a pathogen-free animal facility at the School of Medicine, Shinshu University. Experiments were started at 6 weeks of age after stabilization in the facility. The animals were divided in four groups: control, as-grown MWCNTs and thermally treated MWCNTs at 1800 and $2800^{\circ} \mathrm{C}$ (HTT1800 and HTT2800). Each group consisted of 30 animals and was further subdivided into six subgroups, which were scarified for blood sampling from the heart and skin tissue sampling 4 weeks post-implantation. An incision of about $1 \mathrm{~cm}$ was made on the back skin of each animal under fluothane anesthesia, and $1 \mathrm{mg}$ of each of the tested materials was embedded subcutaneously. Then, the incision was sutured. As the control, $1 \mathrm{ml}$ of physiological saline as replacement of the tested materials was used. On the expected date of blood and tissue sampling, each animal was scarified under deep anesthesia using fluothane. Blood was sampled by cardiac puncture for flow cytometry and the levels of cytokines were determined in peripheral blood. Additionally, skin tissues including the muscle layer were sampled for pathological examination.

\subsection{Flow cytometry}

Sampled blood was stained with antibodies against CD4 and CD8 (BD Bioscience Pharmingen, USA) to sort $\mathrm{T}$ lymphocytes using a flow cytometer (FACS Calibur, Becton Dickinson, USA). Stained immune cells were analyzed using CellQuest software (Becton Dickinson).

\subsection{Measurement of levels of cytokines by ELISA}

A Q-Plex Array (Quansys Biosciences, Logan, Uhta, BioLegend, San Diego, CA) was used for measuring the levels of cytokines in sampled peripheral blood. We measured 9 different cytokines related to inflammatory reactions (i.e., IL-2, IL-3, IL-4, IL-5, IL-6, IL-9, IL-10, IFN- $\gamma$, and TNF $\alpha$, GM-CSF and RANTES) by ELISA with an 
optimal dilution of sampled plasma. The LPS levels of the materials used here were not detectable using an Endospecy kit (Seikagaku Kogyo, Tokyo, Japan).

\subsection{Histology}

For conventional histology, tissues were taken immediately after the sacrifice of the animals, fixed in $10 \%$ formaldehyde, embedded in paraffin, cut into 5 - $\mu \mathrm{m}$-thick sections, and stained with hematoxylin and eosin.

\subsection{Statistical analysis}

Data were shown as mean \pm SE. Significant differences were assessed using the two-tailed Student's t-test and significance was established at the $\mathrm{P}<0.05$ level.

\section{Results and Discussion}

We started this study by examining the types and amounts of various impurities in as-grown nanotubes and how such impurities are removed during high-temperature thermal treatment. Table 1 shows the basic physical and chemical properties as well as impurities of the as-grown tubes and tubes thermally treated at 1800 and $2800^{\circ} \mathrm{C}$.

3.1 Effect of Metallic Impurities: Carbon nanotubes grow through the decomposition of hydrocarbons on nanosized metal particles in a reaction chamber, thereby facilitating the observation of metallic particles at the tip or hollow core of as-grown carbon nanotubes $[14,15]$. Very recently, Hurt et al. carried out a systematic study on the iron or nickel bioavailability [11-13], and revealed that the metallic impurities within SWCNTs induce the evolved toxicity. Generally, the iron phase both in the hollow cores and/or at the tips of as-synthesized carbon nanotubes consist of $\gamma$-iron, $\alpha$-iron, $\mathrm{Fe}_{3} \mathrm{C}$ and $\mathrm{Fe}_{1-\mathrm{x}} \mathrm{S}$ [16]. Noticeably, they are insoluble in hydrochloric acid owing to their complete coverage by protective disordered carbons (Table 1). This is the reason preoxidative 
treatment is needed to remove deposited carbons covering metal particles before treating the particles with hydrochloric acid for dissolution. Thus, it is appropriate to disregard the effect of metallic impurities in the as-grown samples. However, when they are thermally treated at high temperatures up to $1800^{\circ} \mathrm{C}$, the amount of remaining iron consisting of pure iron and iron oxide is less than $80 \mathrm{ppm}$. It is worthwhile to note that iron in the tubes thermally treated at $1800^{\circ} \mathrm{C}$ completely dissolves in hydrochloric acid (see Table 1), indicating that it is present on the outer surface of carbon nanotubes because it diffuses from the inside to the outside and thus may induce toxicity [17]. However, in the tubes thermally treated at $2800^{\circ} \mathrm{C}$, the amount of residual iron is less than $20 \mathrm{ppm}[18]$.

3.2 Effect of Functional Groups: The interface property of carbon nanotubes is of great importance when evaluating the toxicity of carbon nanotubes in in vitro and in vivo assays. Sayes et al. [19] have shown a decreased cytotoxicity with an increased functionality of single-walled carbon nanotubes (SWCNTs) using human dermal fibroblasts. In contrast, Magrez et al. [20] demonstrated an increased toxicity with increasing concentraion of chemical surface groups. Functional groups introduced at the side wall of the tubes are important for dispersing SWCNTs, but are considered impurities themselves. We completely removed functional groups on the side wall of carbon nanotubes by thermally treating as-grown tubes at 1800 and $2800^{\circ} \mathrm{C}$ in argon because they are unstable under these conditions and are evolved as carbon oxides.

3.3 Effect of Disordered Carbons: In growing carbon nanotubes by exposing hydrocarbons to catalytic particles in a reaction chamber, disordered carbons are inevitably deposited on the outer surface of carbon nanotubes [14]. Even though disordered carbons could be removed by exposing as-grown tubes in the temperature 
range of $300-550^{\circ} \mathrm{C}$ or to strong acids, it is experimentally impossible to remove them completely from carbon nanotubes. They consist of small or undulated graphene layers, and in some cases, have some fraction of functional groups at chemically active edge sites of the graphene layers. From the viewpoint of microtexture, disordered carbons are exactly the same as carbon black [21]. Therefore, they are expected to have a similar biological response to carbon black. High-temperature thermal treatment in argon effectively transforms small aromatic rings (blurred images) to long and straight carbon structures (clear images). Kinetically, they are typical graphitizable carbons that develop in crystalline form by high-temperature thermal treatment [22].

3.4 Effect of Dispersing Agents: Since SWCNTs are intrinsically bundled owing to the high van der Waals forces of attraction between adjacent tubes, various dispersing agents have been used to prepare nanotube emulsions before in vitro and in vivo assays. The surface properties of carbon nanotubes could be modified by attaching dispersing agents; however, sodium dodecyl sulfate (SDS) and sodium dodecylbenzene sulfonate (SDBS), which are commonly used for dispersing SWCNTs, are reported to be toxic [23]. Very recently, Morales et al. [24] found that protein-modified carbon nanotubes exhibit reduced pathway activation compared with untreated tubes. Simply stated, dispersing agents are necessary for dispersing highly bundled SWCNTs, despite their being considered impurities themselves because they can markedly alter the surface properties of carbon nanotubes. In this case, we are unable to evaluate the cytotoxicity of pure carbon nanotubes ( $s p^{2}$ carbon unit). It is difficult to prepare an SWCNT emulsion experimentally without using severe oxidative treatment and a dispersing agent. Very recently, Poland et al. [25] reported that long carbon nanotubes induce inflammation and lesions in abdominal cavities, similarly to asbestos. Before injecting a 
nanotube emulsion into the peritoneal cavity of a female, they prepared a nanotube emulsion in a sterile $0.5 \%$ bovine serum albumin (BSA)/saline solution using ultrasonication. Therefore, we could say that they evaluated the nanotube/BSA hybrid structure, not pure carbon nanotubes, according to their protocol. Karajanagi et al. [26] proved the good dispersing ability of BSA for SWCNTs because BSA molecules attach to (or adsorb onto) the surface of SWCNTs in an irregular pattern [27]. Fortunately, the multi-walled carbon nanotubes used in our study have an average diameter of $80 \mathrm{~nm}$ and a low ability to form a bundled structure. Thus, we could prepare a stable nanotube emulsion under mild sonication without chemical treatment and the use of dispersing agents, which is another advantage of the use of pure crystalline MWCNTs.

3.6 Effect of Chlorine Atoms: As a general means of removing metallic impurities and disordered carbons from HiPco-based SWCNTs [28, 29], the combined air oxidation and hydrochloric acid treatment has been commonly used. Air oxidation is effective for etching disordered carbons as well as for opening carbon-covered metal particles at the tip or hollow core of carbon nanotubes, so that hydrochloric acid could easily dissolve metallic impurities. In the dissolution in hydrochloric acid, we found that chlorine atoms are effectively attached to the active sites of carbon nanotubes; that is, the catalytically grown tubes have defect sites that show a high chemical reactivity to chlorine atoms (Fig. S1 (b)). Thus, hydrochloric acid-treated tubes have some chlorine atoms $(0.08$ atomic \%). We expect that the introduced chlorine atoms modify the biocompatibility of carbon nanotubes to some degree. In this sense, hydrochloric acid treatment should be avoided in preparing standardized pure clean carbon nanotubes for use as reference samples.

3.7 Effect of Polycyclic Aromatic Hydrocarbons: The presence of PAHs is inevitable in 
catalytically growing carbon nanotubes. Moreover, 15 aromatic hydrocarbons including four different kinds of toxic PAH are formed in nanotube synthesis [30]. Here, we proved that tubes thermally treated at 1800 and $2800^{\circ} \mathrm{C}$ in argon have no small molecules, even though as-grown tubes have a portion of small molecules. We also confirmed the absence of low-molecular-weight molecules in tubes thermally treated at 1800 and $2800^{\circ} \mathrm{C}$ by analyzing acetone-dissolved solutions using GC-MS (Fig. S2). Thus, we are able to disregard the effect of PAHs when evaluating the biological responses of thermally treated tubes in our study, since low-molecular-weight PAHs are easily removed from the tubes below $500^{\circ} \mathrm{C}$ in an inert atmosphere.

3.8 Purity of Carbon Nanotubes: We determined the purity of carbon nanotubes with regard to carbon nanoparticles in our sample because the as-produced spherical carbon black exhibits moderate toxicity [31]. The nanotube purity of our sample is ca. $98 \%$ (based on detailed SEM observations); in addition, the carbon nanoparticles are dissimilar to carbon black particles. For example, they have no disordered carbons with active dangling bonds, PAHs, or oxygen-containing functional groups because they are thermally treated at high temperatures up to $2800^{\circ} \mathrm{C}$ in argon. Thus, although they are morphologically similar to carbon black, they are dissimilar to carbon black from the viewpoint of microtexture. The surface property of nanosized materials is the key factor for evaluating cytotoxicity.

3.9 Examination of Toxicity of Carbon Nanotubes: We chose subcutaneous implantation because subcutaneous insult could trigger systemic toxicities. Thus, the application of blood screening methods for evaluating the systemic response to particle exposure of the local organs such as the lungs will aid in predicting possible toxicity and, consequently, in establishing strategies for the safe handling of nanomaterials. In 
addition to serum parameters, the levels of cytokines, which come in contact with all tissues and contribute to homeostasis, provide valuable information on the health or disease status of the body.

Note that high-temperature thermal treatment is an effective means of removing impurities within the tubes [16, 18]. Experimentally, contaminated (as-grown), iron-contaminated $\left(\mathrm{HTT}=1800^{\circ} \mathrm{C}\right)$ and highly pure and clean $\left(\mathrm{HTT}=2800^{\circ} \mathrm{C}\right)$ tubes were subcutaneously implanted into mice ( $n=5$ per group) for up to 4 weeks. The mice implanted with the as-grown and iron-contaminated tubes exhibited severe hair loss (Figs. 1 (b, c)) and thick, hard callus formation (Fig. 1 (f, g)) (Fig. S3 (b, c)). However, highly pure and clean tubes-implanted mice do not experience any skin hair loss (Fig. S3 (d)).

Histologically, the as-grown tubes showed inflammatory cells located around them (Fig. 1 (j)) that were encapsulated tightly by granuloma tissue. A prominent inflammatory component and a marked follicular dystrophy appeared near these hair loss regions. Perifollicular inflammatory cells progressively focused on hair follicles, in association with an enhanced disruption of root sheath growth and hair fiber production. Such inflammatory aspects for the iron-contaminated tubes (Fig. $1(\mathrm{k})$ ) were less pronounced than those for the as-grown tubes. The highly clean tubes showed a slight cell infiltration and a slight granulomatous reaction.

Additionally, with regard to the changes in the $\mathrm{CD}^{+}$level, $\mathrm{CD} 8^{+}$level, and $\mathrm{CD}^{+} / \mathrm{CD}^{+}$ratio of peripheral T-cells for the subcutaneously implanted tubes (Fig. 2), we found no marked changes in $\mathrm{CD}^{+}$level for any of the samples, but we observed a high $\mathrm{CD}^{+}$level and a high $\mathrm{CD} 4^{+} / \mathrm{CD}^{+}$ratio for the as-grown and iron-contaminated tubes. 
We have previously reported that the major histocompatibility complex (MHC) class-I pathway of the antigen-antibody response system is enhanced in SWCNTs and that both MHC classes I and II are inactivated in MWCNTs [7]. Here, we showed that MWCNTs inhibited both MHC class-I and class-II pathways. Also, the contribution of the T cell subset to the MWCNTs used here depends on the Th2 pathway, which can be reflected in the time-course changes in peripheral $\mathrm{CD} 4^{+}, \mathrm{CD}^{+}$and cytokine levels. We also showed that immunological reactions in subcutaneously MWCNT-implanted mice are markedly enhanced when a variety of impurities is within the tubes. In addition, we showed the induction of different biological responses of the peripheral T-cell subset and several kinds of peripheral cytokine to MWCNTs containing different types of impurities (see Figs. 3 and S4).

Additionally, the increased IL-4 level in mice with allergic dermatitis was closely related to the extent of exacerbation of allergic dermatitis, which is quite consistent with previous study [32]. Furthermore, IL-10 is an important anti-inflammatory cytokine for alleviating allergic dermatitis; it combines with IFN- $\gamma$ and then counteracts IL-4 of allergic dermatitis. Thepen et al. [33] suggested that Th2 cells play an important role in the pathogenesis of allergic dermatitis in humans by releasing cytokines that mediate, promote, and maintain the inflammatory cascade, and consequently the occurrence of skin lesions. Also, Zhao et al. [34] ascribed an increased $\mathrm{CD} 4^{+} / \mathrm{CD} 8^{+}$ratio from spleens of $\mathrm{C} 57 \mathrm{BL} / 6$ mice with induced allergic dermatitis to a decreased in the number of $\mathrm{CD} 8^{+}$ cells, an event that resembles Th2-cell-mediated atopic dermatitis in human [35]. Hawrylowicz and O'Garra [36] also observed an increased IL-4 level and decreased IL-10 and IFN- $\gamma$ levels in a mouse model in their study of allergic dermatitis. Based on such studies, our model of subcutaneous nanotube implantation demonstrated here is 
considered to be useful for evaluating the biocompatibility of carbon nanotubes.

Histologically, dystrophic hair follicles are the focus of peri- and intra-follicular inflammatory infiltrations in highly contaminated MWCNT-implanted mice. Although we did not investigate the immunohistological aspects on the section of samples, histopathologic examination suggested a significant infiltration of mainly $\mathrm{CD}^{+}$and $\mathrm{CD}^{+}$cells in and around the hair-loss (alopecia) region [7, 35, 37-39].

We clearly showed that alopecia was induced in the mice implanted subcutaneously with as-grown-MWCNT (having a variety of impurities). Moreover, we showed a significant decrease in the number of $\mathrm{CD}^{+} \mathrm{T}$ helper cells and a significant increase in the levels of preinflammatory cytokines related to the pathway. Following dermatological investigations of the alopecia, the local skin of mice exhibiting alopecia showed upregulation of IL-4 in the histological section on immunohistochemistry [40-46]. The preinflammatory cytokines IL-6 and TNF $\alpha$ were expressed at increased levels in only the mice showing alopecia. Furthermore, the expression levels of the Th1and Th2-associated cytokines IL-10 and IL-4 as well as IL-12 and IFN- $\gamma$ were elevated in the mice showing alopecia. The etiology of alopecia remains to be unequivocally defined; however, there is increasing evidence of alopecia being an immunological disturbance [42]. In this study, we showed that impurities within the tubes induce severe immunological reactions, not only on the local skin area near the implanted material, but also in sites of systemic immunological responses. As-grown tubes induced extreme hair loss and abrupt increases in the levels of Th1- and Th2-associated cytokines (i.e., IL-4, IL-6, IL-10 and IFN- $\gamma$ ) [42]. In addition, we found that the as-grown-tube-implanted mice showed significant increases in IL-3, IL-5 and IL-9, but not IL-12, indicating that the main pathway of immunological reactions with a variety 
of impurities within the tubes involves Th2-associated toxic action. Interestingly, for the tubes thermally treated at $1800^{\circ} \mathrm{C}$, the levels of cytokines such as GM-CSF and chemokines such as RANTES increased significantly very similarly to those for the as-grown tubes, suggesting that these cytokines is highly sensitive to an iron on the outer surface of the tubes.

As regards the effect of metallic impurities, Lam et al. [5] reported that pulmonary disturbances may be caused by the activation of metal catalysts within the tubes. Shvedova et al. [4] suggested that the MWCNT exposure of human epidermal keratinocytes causes oxidative stress and cellular toxicity, as indicated by the formation of free radicals, the accumulation of peroxidative products, antioxidant depletion, and the loss of cell viability after $18 \mathrm{~h}$ of MWCNT exposure in vitro. Additionally, they showed structural and morphological changes in cultured cells. Their results indicate that unpurified MWCNT exposure may accelerate oxidative stress and induce dermal toxicity in exposed workers. Monteiro-Riviere et al. [6] studied the toxicity of MWCNTs to human epidermal keratinocytes in vitro, and suggested that chemically unmodified MWCNTs are present within cytoplasmic vacuoles of keratinocytes at all time points. Also, MWCNTs induce the release of proinflammatory cytokines such as IL-8 from cells, resulting in an irritation response on the skin and a possible apoptosis. Martin et al. [47] suggested that transition metals can be highly oxidative in biological systems. In vivo, transition metals still have little effect on macrophages, but may have a proinflammatory effect on epithelial cells. Particles can affect both macrophages and epithelial cells, which may result in a potential enhancement of inflammation. Also, Weis et al. [48] suggested that IL-4-mediated enhanced uptake and storage of iron in macrophages represent a control mechanism during chronic inflammatory processes to 
prevent progressive tissue damage by toxic macrophage products. Iron sequestration by macrophages following exposure to IL-4 may in this way suppress the formation of highly toxic hydroxyl radicals via the catalytic action of iron, and thus exert a protective effect on neighboring cells. It remains to be determined to what extent the anti-inflammatory actions of Th2 cytokines, such as IL-4, are due to their influence on macrophage iron metabolism, limiting the potentially toxic effects of macrophage products and modulating the Th1-mediated immune effect or function. Therefore, in the future it is necessary to determine the mechanism underlying oxidative stress caused by reactive metal species within the carbon nanotubes at the cellular level in vitro. It is also necessary to clarify a complex network of interactions between macrophages and peptide mediators resulting in oxygen-radical-mediated tissue injury for more accurate evaluation of the biocompatibility of carbon nanotubes.

\section{Conclusions}

Here, we demonstrated the strong dependence of the types and amounts of impurities within carbon nanotubes on the evolved toxicity of such tubes. We found that the origins of the toxicities acquired from as-grown tubes and tubes thermally treated at $1800^{\circ} \mathrm{C}$ are different. Disordered carbon (including structural defects like dangling bonds) and PAHs in as-grown tubes give rise to acute toxicity, similar to that of commercially available carbon black. However, high-temperature thermal treatment at $1800^{\circ} \mathrm{C}$ in argon induces comprehensive changes of carbon nanotubes; for example, functional groups are decomposed as evolved gases, toxic PAHs as well as disordered carbons (being structurally unstable) evaporate are easily transformed into crystalline carbons, structural defects are annealed, iron particles diffuse from the inside to the 
outside, and the small amount of iron (ca. $80 \mathrm{ppm}$ ) is present on the outer surface of carbon nanotubes. Even though the remaining iron content is low, metallic iron can oxidize to release water-soluble ions that can serve as redox catalysts for the generation of reactive oxygen species. However, extremely pure tubes prepared by thermal treatment at $2800^{\circ} \mathrm{C}$ show excellent property in terms of biocompatibility compared with unpurified carbon nanotubes.

\section{Acknowledgements}

This work was partially supported by the CLUSTER project (second stage) and a grant for Specially Promoted Research (No. 19002007) from the Ministry of Education, Culture, Sports, Science and Technology of Japan and a grant from the New Energy and Industrial Technology Development Organization of Japan (NEDO) for "Evaluating risks associated with manufactured nanomaterials" (P06041). 


\section{References}

[1] Dresselhaus MS, Dresselhaus G., Eklund, PC. Science of Fullerenes and Carbon Nanotubes. Academic: San Diego. 1996.

[2] Baughman RH, Zakhidov AA, de Heer, WA. Carbon nanotubes - the route toward applications -. Science 2002; 297: 787-92.

[3] Robert, F. Nanomaterials show signs of toxicity. Science 2003; 300: 243.

[4] Shvedova AA, Castranova V, Kisin E, Schwegler-Berry D, Murray A, Gandelsman $\mathrm{V}$, et al. Exposure to carbon nanotube material: Assessment of nanotube cytotoxicity using human keratinocyte cells. Toxicol Environ Health A 2003; 66: 1909-26.

[5] Lam C-W, Junes JT, McCluskey R, Hunter RL. Pulmonary toxicity of single-wall carbon nanotubes in mice 7 and 90 days after intratracheal instillation. Toxicol Sci 2004; 77: 126-34.

[6] Monteiro-Riviere NA, Nemanich RJ, Inman AO, Wang YY, Riviere JE, Multi-walled carbon nanotube interactions with human epidermal keratinocytes. Toxicol Lett 2005; 155: 377-84.

[7] Koyama S, Endo M, Kim YA, Hayashi T, Yanagisawa T, Osaka K, et al. Role of systemic T-cells and histopathological aspects after subcutaneous implantation of various carbon nanotubes in mice. Carbon 2006; 44: 1079-92.

[8] Pulskamp K, Diabaté S, Krug HF, Carbon nanotubes show no sign of acute toxicity but induce intracellular reactive oxygen species in dependence on contaminants. Toxicol Lett 2007; 168: 58-74.

[9] Shvedova AA, Kisin ER, Mercer R, Murray AR, Johnson VJ, Potapovich AI, et al. Unusual inflammatory and fibrogenic pulmonary responses to single-walled carbon nanotubes in mice. Am J Physiol Lung Cell Mol Physiol 2005; 289: L698-L708. 
[10]Kagan VE, Tyurina YY, Tyurin VA, Konduru NV, Potapovich AI, Osipov AN, et al. Direct and indirect effects of single walled carbon nanotubes on RAW 264.7 macrophages: Role of iron. Toxicol Lett 2006; 165: 88-100.

[11]Guo L, Morris DG, Liu X, Vaslet C, Hurt RH, Kane AB. Iron bioavailability and redox activity in diverse carbon nanotube samples. Chem Mater 2007; 19:3472-78.

[12]Liu X, Gurel V, Morris D, Murray DW, Zhitkovich A, Kane AB, et al. Bioavailability of nickel in single-wall carbon nanotubes. Adv Mater 2007; 19:2790-6.

[13]Liu X, Guo L, Morris D, Kane AB, Hurt RH. Targeted removal of bioavailable metal as detoxification strategy for carbon nanotubes. Carbon 2008; 46;489-500.

[14] Oberlin A, Endo M, Koyama T. Filamentous growth of carbon through benzene decomposition. J Crys Grow 1976; 32: 335-49.

[15] Endo M. Grow carbon fibers in the vapor phase. Chem Tech 1988; 18: 568-76.

[16]Chen J, Kuno A, Matsuo M, Tsukada T, Tamura T, Osato K, et al. Removal of entrapped iron compounds from isothermally treated catalytic chemical vapor deposition derived multi-walled carbon nanotubes. Carbon 2008; 46: 391-6.

[17]Hiraishi H, Terano A, Ota S, Mutoh H, Razandi M, Sugimoto T, et al. Role for iron in reactive oxygen species-mediated cytotoxicity to cultured rat gastric mucosal cells. Am J Physiol Gastrointest Liver Physiol 1991; 260: G556-63.

[18]Endo M, Kim YA, Hayashi T, Nishimura K, Matusita T, Miyashita K, et al. Vapor-grown carbon fibers (VGCFs): Basic properties and their battery applications. Carbon 2001; 39: 1287-97.

[19] Sayes CM, Liang F, Hudson JL, Mendez J, Guo W, Beach JM, et al. Functionalization density dependence of single-walled carbon nanotubes 
cytotoxicity in vitro. Toxicol Lett 2006; 161: 135-42.

[20] Magrez A, Kasas S, Salicio V, Pasquier N, Seo JW, Celio M, et al. Cellular toxicity of carbon-based nanomaterials. Nano Lett 2006; 6: 1121-5.

[21]Donnet J-B, Bansal RC, Wang M-J. Carbon Black. New York: Science and Technology. 1993.

[22]D.B. Fischebach, The kinetics and mechanism of graphitization. In: Walker PL, editor. Chemistry and physics of carbon, Vol 7, New York; Dekker. 1971; 1-97.

[23]Dong L, Joseph KL, Withowski CM, Craig MM. Cytotoxicity of single-walled carbon nanotubes suspended in various surfactants. Nanotechnology 2008; 19: 255702.

[24] Salvador-Morales C, Basiuk EV, Basiuk VA, Green MLH, Sim RB. Effects of covalent functionalisation on the biocompatibility characteristics of multi-walled carbon nanotubes. J Nanosci Nanotech 2008; 8: 2347-56.

[25] Poland CA, Duffin P, Kinloch I, Maynard A, Wallace WAH, Seaton A, et al. A pilot toxicology study of single-walled carbon nanotubes in a small sample of mice. Nat Nanotech 2008; 3: 216-21.

[26] Karajanagi SS, Yang H, Asuri P, Sellitto E, Dordick JS, Kane RS. Protein-assisted solubilization of single-walled carbon nanotubes. Langmuir 2006; 22: 1392-5.

[27] Goldberg-Oppenheimer P, Regev O. Exploring a nanotube dispersion mechanism with gold-labeled proteins via cryo-TEM Imaging. Small 2007; 3: 1894-9.

[28] Gorelik O, Nikolaev P, Arepalli S. Purification procedures for single-wall carbon nanotubes. NASA Contractor Report. NASA/CR-2000-208926.

[29] Yang CM, Kaneko Y, Yudasaka Y, Iijima S. Effect of purification on pore structure of HiPco single-walled carbon nanotube aggregates. Nano Lett 2002; 2: 385-8. 
[30]Petkewich R. Nanotube synthesis emits toxic by-products. C \& EN 2007; August: 12.

[31]de Haar C, Hassing I, Bol M, Bleumink R, Pieters R, Ultrafine carbon black particles cause early airway inflammation and have adjuvant activity in a mouse allergic airway disease model. Toxico Sci 2005; 87: 409-18.

[32] Seki Y, Inoue H, Nagata N, Hayashi K, Fukuyama S, Matsumoto K, et al. SOCS-3 regulates onset and maintenance of $\mathrm{TH} 2$-mediated allergic responses. Nat Med 2003; 9: 1047-54.

[33] Thepen T, Langeveld-Wildschut EG, Bihari IC, van Wichen DF, van Reijsen FC, Mudde GC, et al. Biphasic response against aeroallergen in atopic dermatitis showing a switch from an initial $\mathrm{T}_{\mathrm{H} 2}$ response to a $\mathrm{T}_{\mathrm{H} 1}$ response in situ: An immunocytochemical study. J Allergy Clin Immunol 1996; 97(3): 828-37.

[34]Zhao L, Jin H, She R, Hu Y, Xiao C, Yu Y, et al. A rodent model for allergic dermatitis induced by flea antigens. Vet Immunol Immunopathol 2006; 114: 285-96.

[35]Ranki A, Kianto U, Kanerva L, Tolvanen E, Johansson E. Immunohistochemical and electron microscopic characterization of the cellular infiltrate in alopecia (areata, totalis, and universalis). J Invest Dermatol 1984; 83: 7-11.

[36] Hawrylowicz CM, O'Garra A. Potential role of interleukin-10-secreting regulatory T cells in allergy and asthma. Nat Rev Immunol 2005; 5: 271-83.

[37] Gupta AK, Ellis CN, Cooper KD, Nickoloff BJ, Ho VC, Chan LS, et al. Oral cyclosporine for the treatment of alopecia areata. A clinical and immunohistochemical analysis. J Am Acad Dermatol 1990; 22: 242-50.

[38]Perret C, Wiesner-Menzel L, Happle R. Immunohistochemicalanalysis of T-cell subsets in the peribulbar andintrabulbar infiltrates of alopecia areata. Acta Derm 
Venereol 1984; 64: 26-30.

[39] Todes-Taylor N, Turner R, Wood GS, Stratte PT, Morhenn VB. T cell subpopulations in alopecia areata. J Am Acad Dermatol 1984; 11: 216-23.

[40]Chan LS, Vanderlugt CJ, Hashimoto T, Nishikawa T, Zone JJ, Black MM, et al. Epitope spreading: lessons from autoimmune skin diseases. J Invest Dermatol 1998; 110: 103-9.

[41] Katagiri K, Arakawa S, Hatano Y. TGF- $\alpha$ and IFN- $\gamma$ mRNA of the peripheral blood mononuclear cells in patients with alopecia areata in comparison to those in patients with atopic dermatitis. Arch Dermatol Res 2007; 298: 397-401.

[42] McElwee KJ, Silva K, Boggess D, Bechtold L, King LE, Sundberg JP. Alopecia areata in $\mathrm{C} 3 \mathrm{H} / \mathrm{HeJ}$ mice involves leukocyte-mediated root sheath disruption in advance of overt hair loss. Vet Pathol 2003; 40: 643-50.

[43] McElwee, KJ, Spiers EM, Oliver RF. Restoration of hair growth in the DEBR model of alopecia areata after invivo depletion of CD41 cells. J Dermatol 1999; 140: $432-7$.

[44] Sundberg JP, Cordy WR, Jr King LE. Alopecia areata in aging C3H/HeJ mice. J Invest Dermatol 1994; 102: 847-56.

[45] Sundberg JP, Boggess D, Silva KA, McElwee KJ, Jr King LE, Li R, et al. Alopecia areata in aging $\mathrm{C} 3 \mathrm{H} / \mathrm{HeJ}$ mice. J Invest Dermatol 2003; 120: 771-5.

[46]Zöller M, McElwee KJ, Engel P, Hoffmann R. Transient CD44 variant isoform expression and reduction in $\mathrm{CD} 4(1) / \mathrm{CD} 25(1)$ regulatory $\mathrm{T}$ cells in $\mathrm{C} 3 \mathrm{H} / \mathrm{HeJ}$ micewith alopecia areata. J Invest Dermatol 2002; 118: 983-82.

[47] Martin LD, Krunkosky TM, Dye JA, Fischer BM, Jiang NF, Rochelle LG, et al. The role of reactive oxygen and nitrogen species in the response of airway epithelium to 
particulates. Environ Health Perspect 1997; 105: 1301-7.

[48] Weiss G, Bogdan C, Hentze MW. Pathways for the regulation of macrophage iron metabolism by the anti-Inflammatory cytokines IL-4 and IL-13. J Immunol 1997; 158: $420-5$. 
Table 1 Basic characteristic of as-grown and thermally treated multi-walled carbon nanotubes at 1800 and $2800^{\circ} \mathrm{C}$, respectively.

\begin{tabular}{|c|c|c|c|c|}
\hline Item & As grown & $\mathrm{HTT}=1800^{\circ} \mathrm{C}$ & $\mathrm{HTT}=2800^{\circ} \mathrm{C}$ & Testing method \\
\hline Diameter (nm) & $100-150$ & $100-150$ & $100-150$ & FE-SEM \\
\hline Length $(\mu \mathrm{m})$ & $10-20$ & $10-20$ & $10-20$ & FE-SEM \\
\hline $\mathrm{d}_{002}$ & - & - & 0.339 & $\begin{array}{c}\text { X-ray } \\
\text { diffraction }\end{array}$ \\
\hline $\mathrm{R}\left(I_{D} / I_{G}\right)^{\mathrm{a})}$ & 1.041 & 0.855 & 0.051 & $\begin{array}{c}\text { Raman } \\
\text { spectroscopy }\end{array}$ \\
\hline $\begin{array}{l}\text { Specific surface area } \\
\left(\mathrm{m}^{2} / \mathrm{g}\right)\end{array}$ & - & 26 & 13 & $\mathrm{~N}_{2}$ adsorption \\
\hline Real density $\left(\mathrm{g} / \mathrm{cm}^{3}\right)$ & - & - & 2.09 & Pycnometer \\
\hline Fe content (ppm) & 12000 & 80 & $<20$ & ICP-MS \\
\hline $\begin{array}{l}\text { Soluble iron content } \\
(\%)^{\text {b) }}\end{array}$ & 0 & 91 & 100 & ICP-MS \\
\hline $\begin{array}{l}\text { Polycyclic aromatic } \\
\text { hydrocarbons } \\
(\text { wt } \%)^{\text {b) }}\end{array}$ & 0.19 & None & None & $\begin{array}{c}\text { GC-MS } \\
\text { spectroscopy }\end{array}$ \\
\hline $\begin{array}{l}\text { Oxidation } \\
\text { temperature }\left({ }^{\circ} \mathrm{C}\right)^{\mathrm{d})}\end{array}$ & 630 & 720 & 820 & TGA \\
\hline
\end{tabular}

a) $\mathrm{R}$ refers to the intensity of $\mathrm{D}$ band over the intensity of $\mathrm{G}$ band

b) We have determined the dissolved amount of iron by refluxing $5 \mathrm{~g}$ of nanotubes in hydrochloric acid $(0.6 \mathrm{~N})$ for $25 \mathrm{hrs}$.

c) We have measured acetone-soluble components

d) We have determined the oxidation temperatures from the first derivatives of the TGA curves 


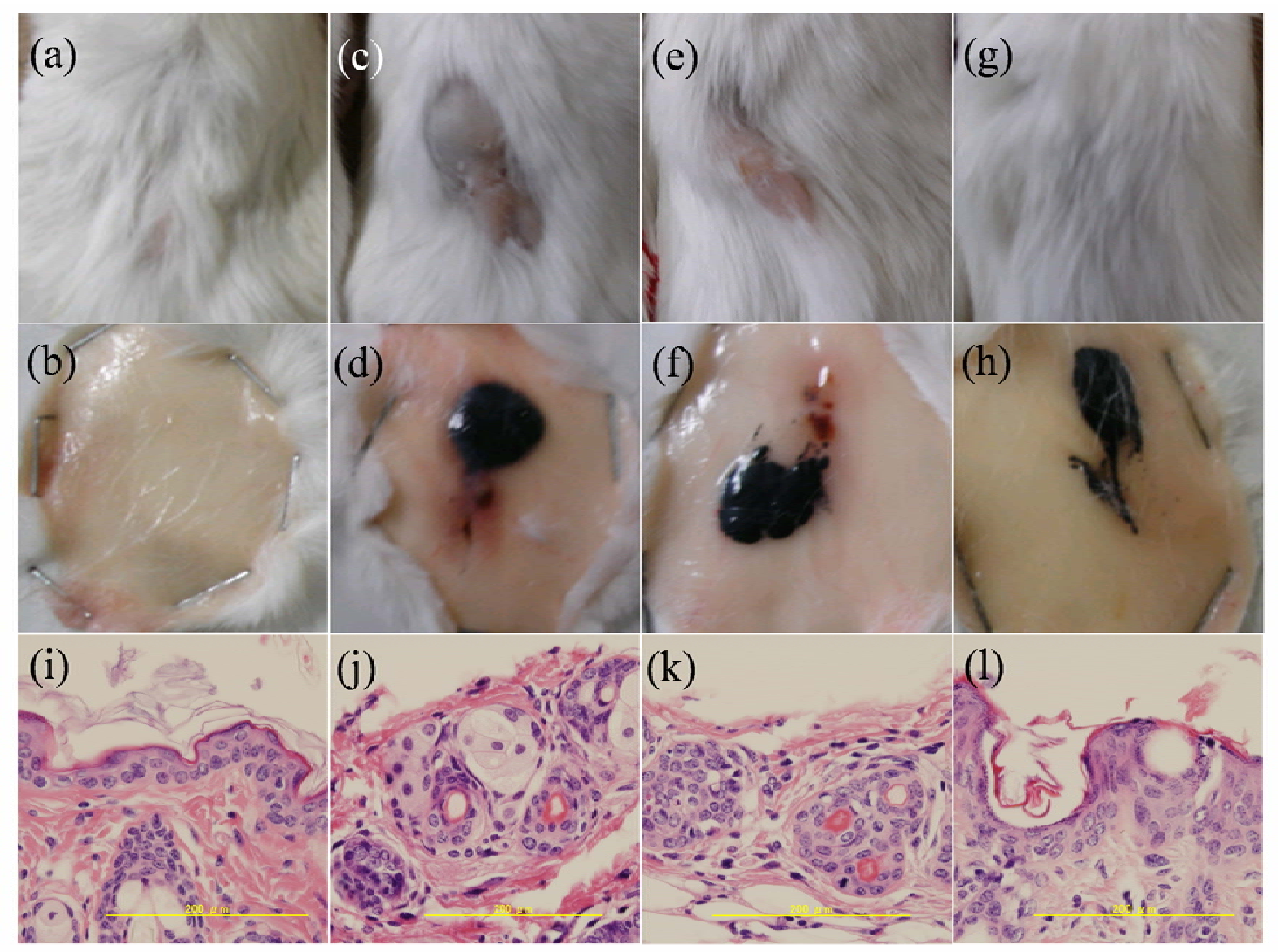

Figure 1 Changes in hair, skin and histology in mice implanted subcutaneously with as-grown $(b, f, j)$, partially clean $(c, g, k)$ and highly clean $(g, h, 1)$ carbon nanotubes for up to 4 weeks versus control (a, e, i). Note that the more impurities, the more severe occurrence of immunological toxicity and alopecia. 

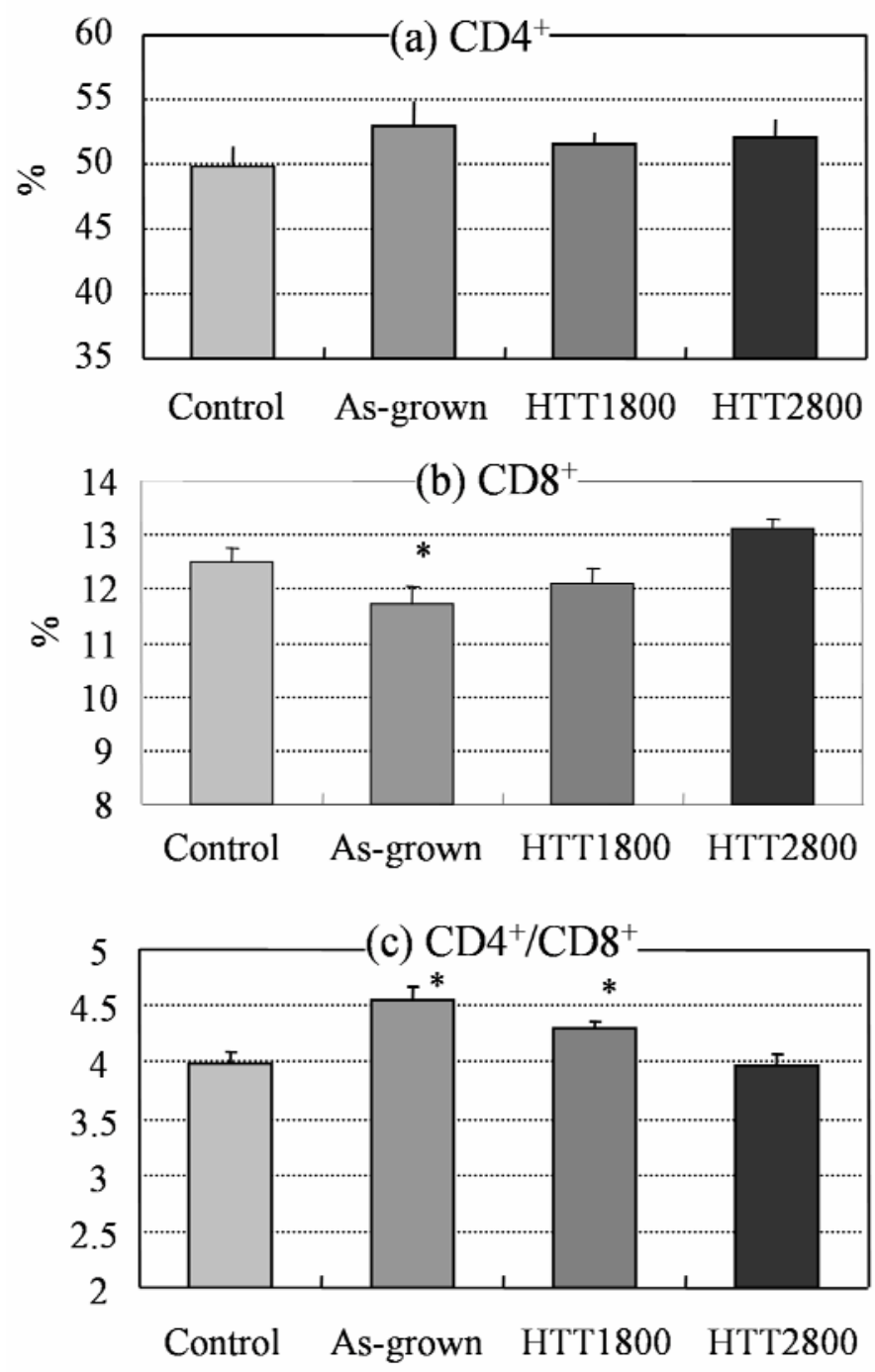

Figure 2 Time-dependent changes in (a) $\mathrm{CD} 4^{+}$, (b) $\mathrm{CD} 8^{+}$and (c) $\mathrm{CD} 4^{+} / \mathrm{CD} 8^{+}$ratio for the subcutaneously MWCNT-implanted mice. Asterisks indicate statically significant difference $(\mathrm{P}<0.05)$ versus control. 

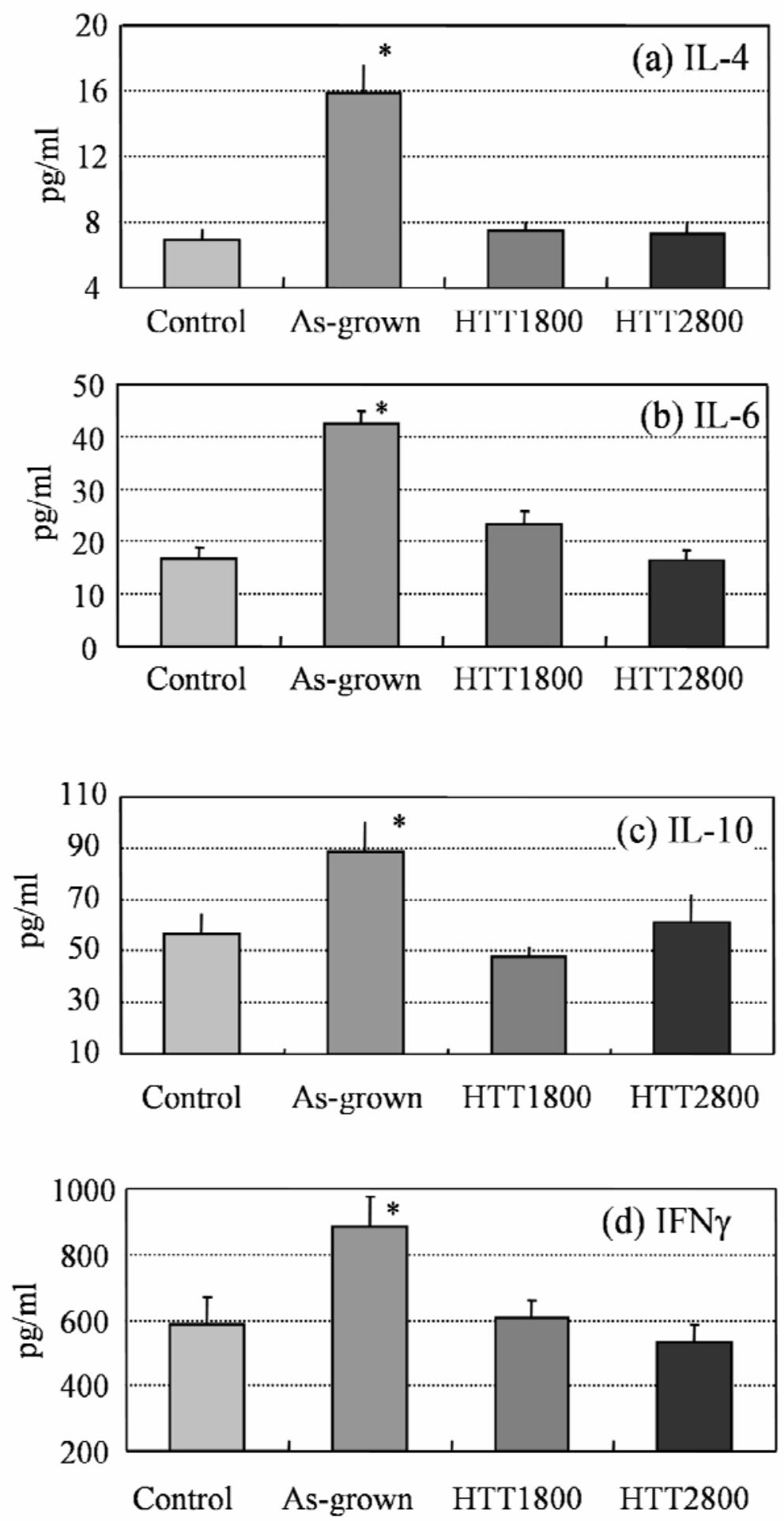

Figure 3 Time-dependent changes in (a) IL-4, (b) IL-6, (c) IL-10 and (d) IFN- $\gamma$ for the mice implanted subcutaneously with MWCNTs. Asterisks indicate statically significant difference $(\mathrm{P}<0.05)$ versus control. 

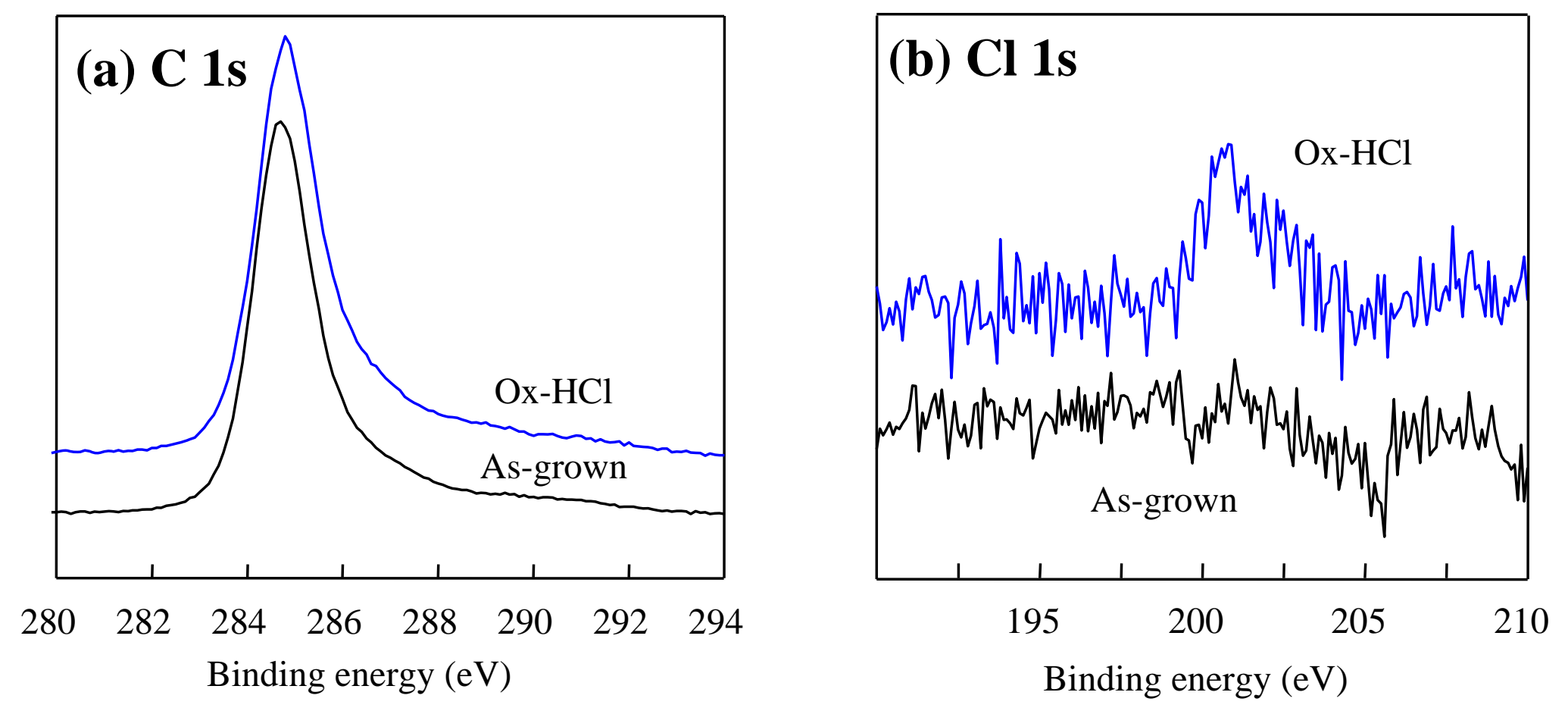

Figure S1. (a) C1s and (b) Cl 1s XPS spectra of as-grown and purified (air oxidation and hydrochloric acid treatment) tubes 


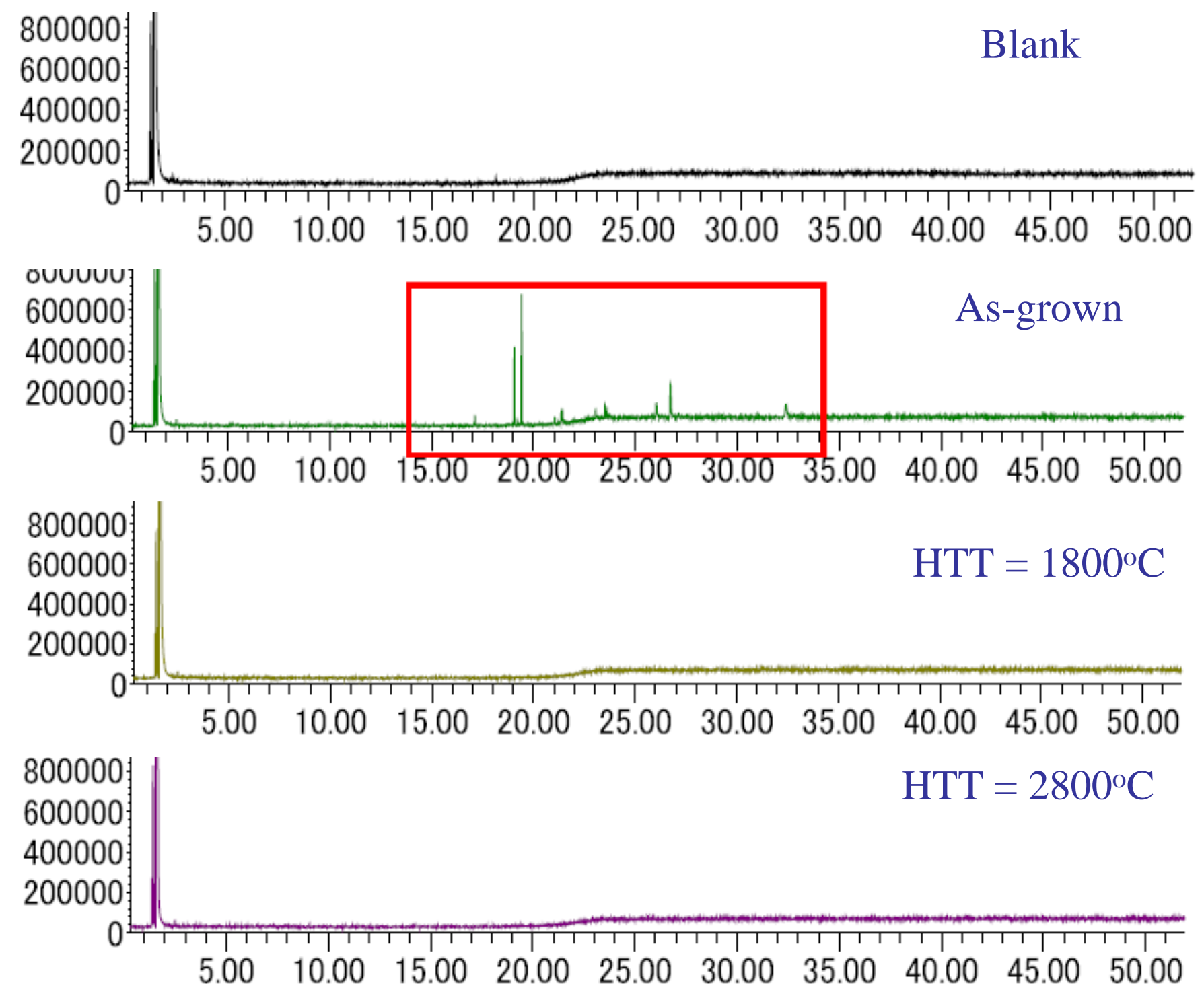

Figure S2. GC-MS spectra of blank, acetone dissolved components for as-grown, thermally treated tubes at 1800 and $2800^{\circ} \mathrm{C}$ in argon. 


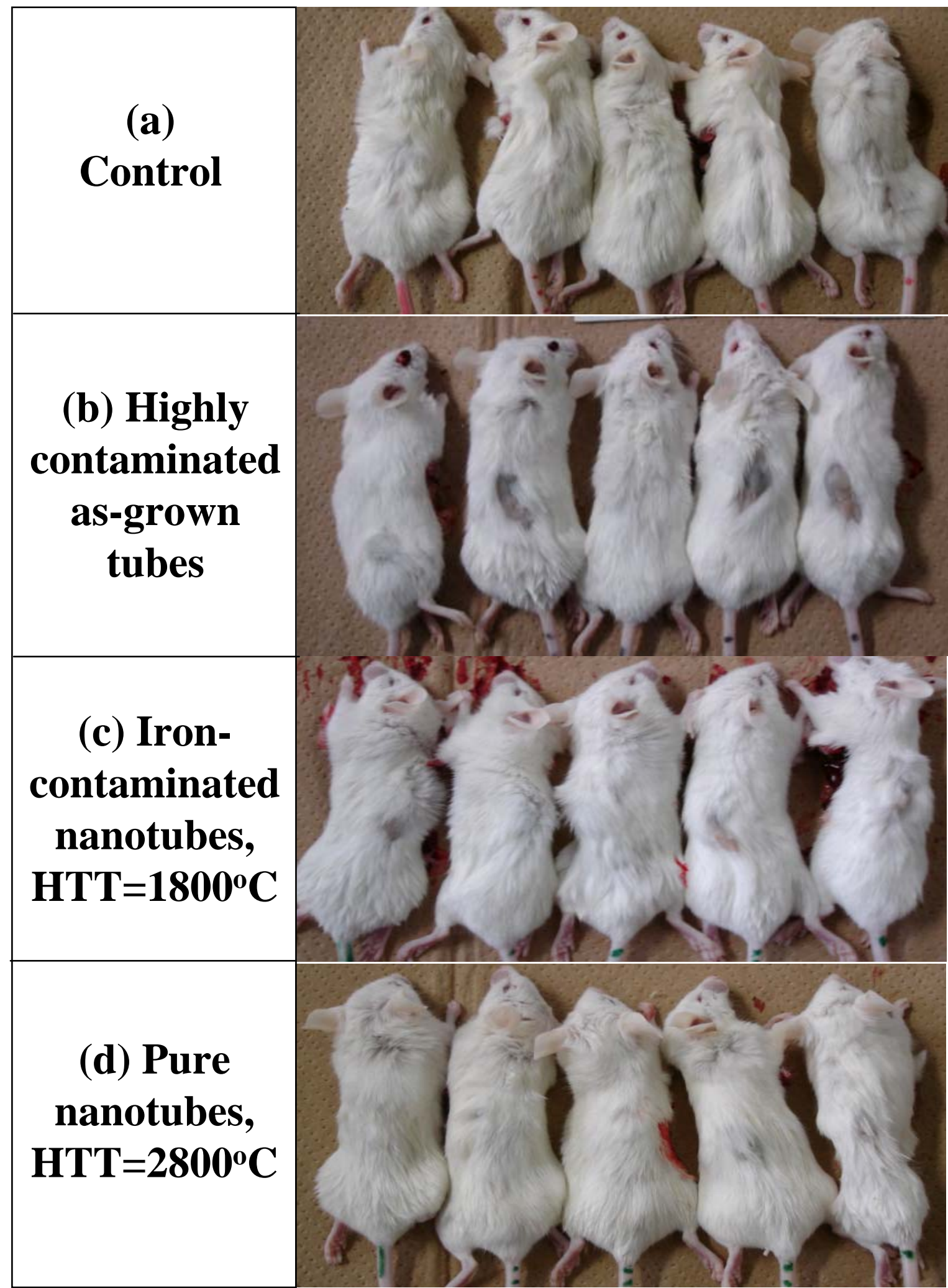

Figure S3. The changes of hair and skin for subcutaneously as-grown (b), partially clean (c) and highly clean (d) implanted mice up to 4 weeks versus control (a), 

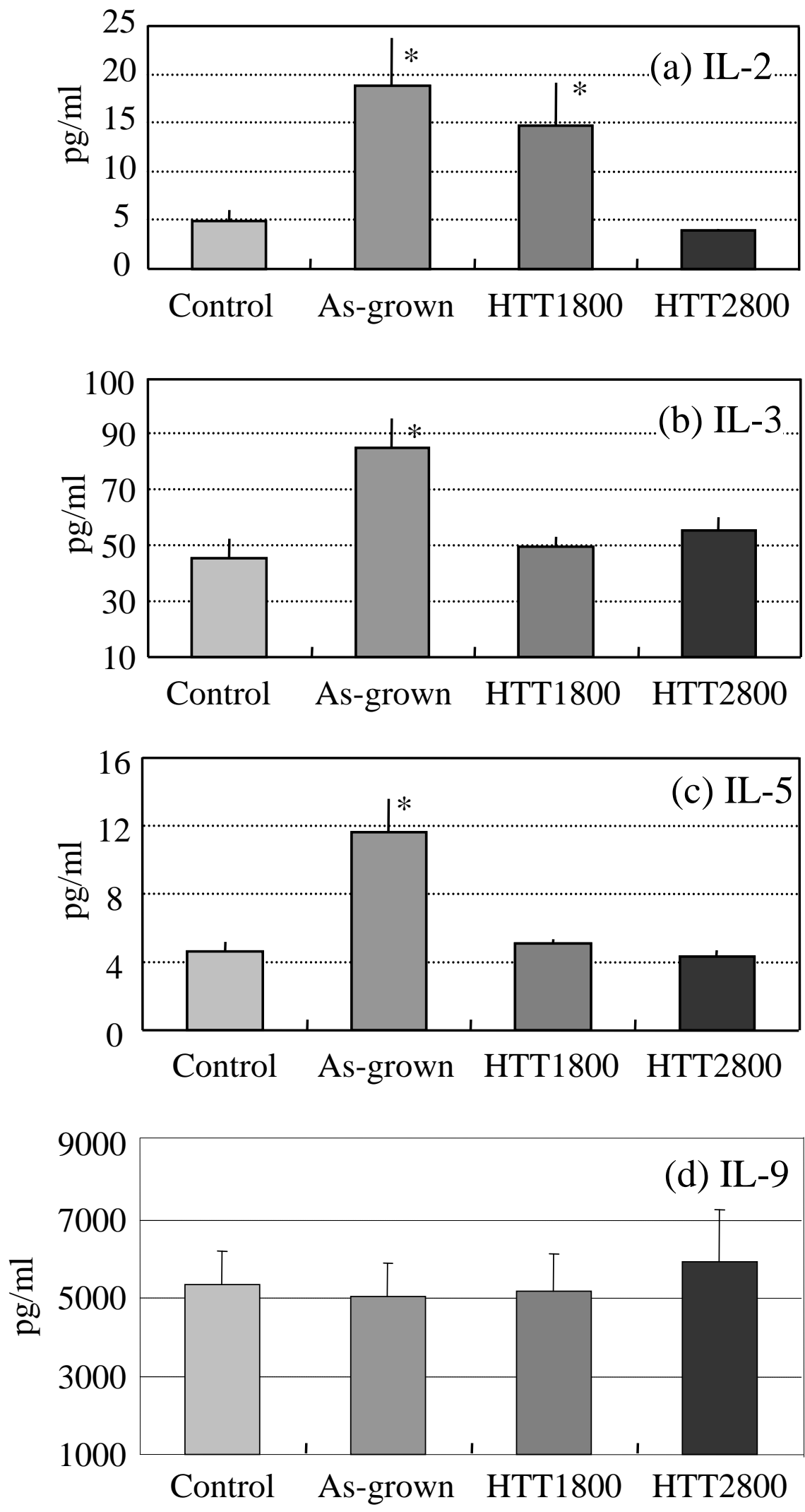


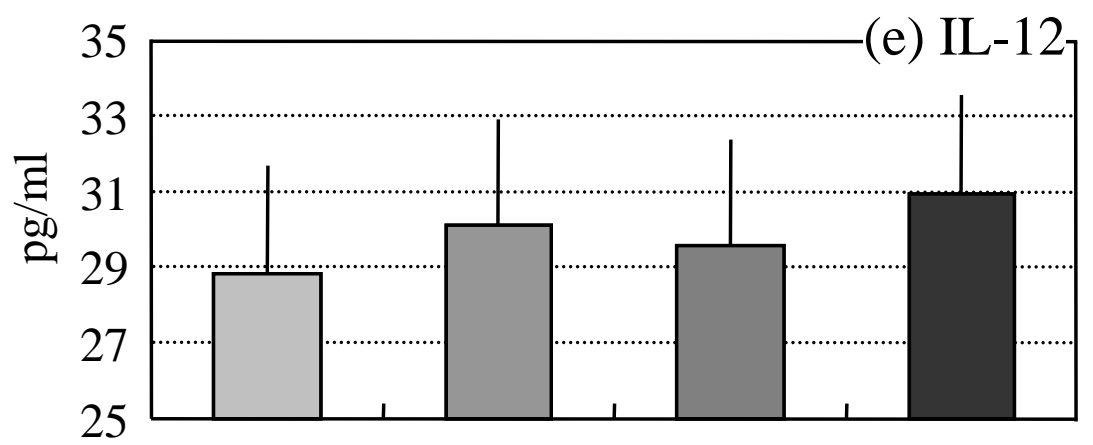

Control As-grown HTT1800 HTT2800
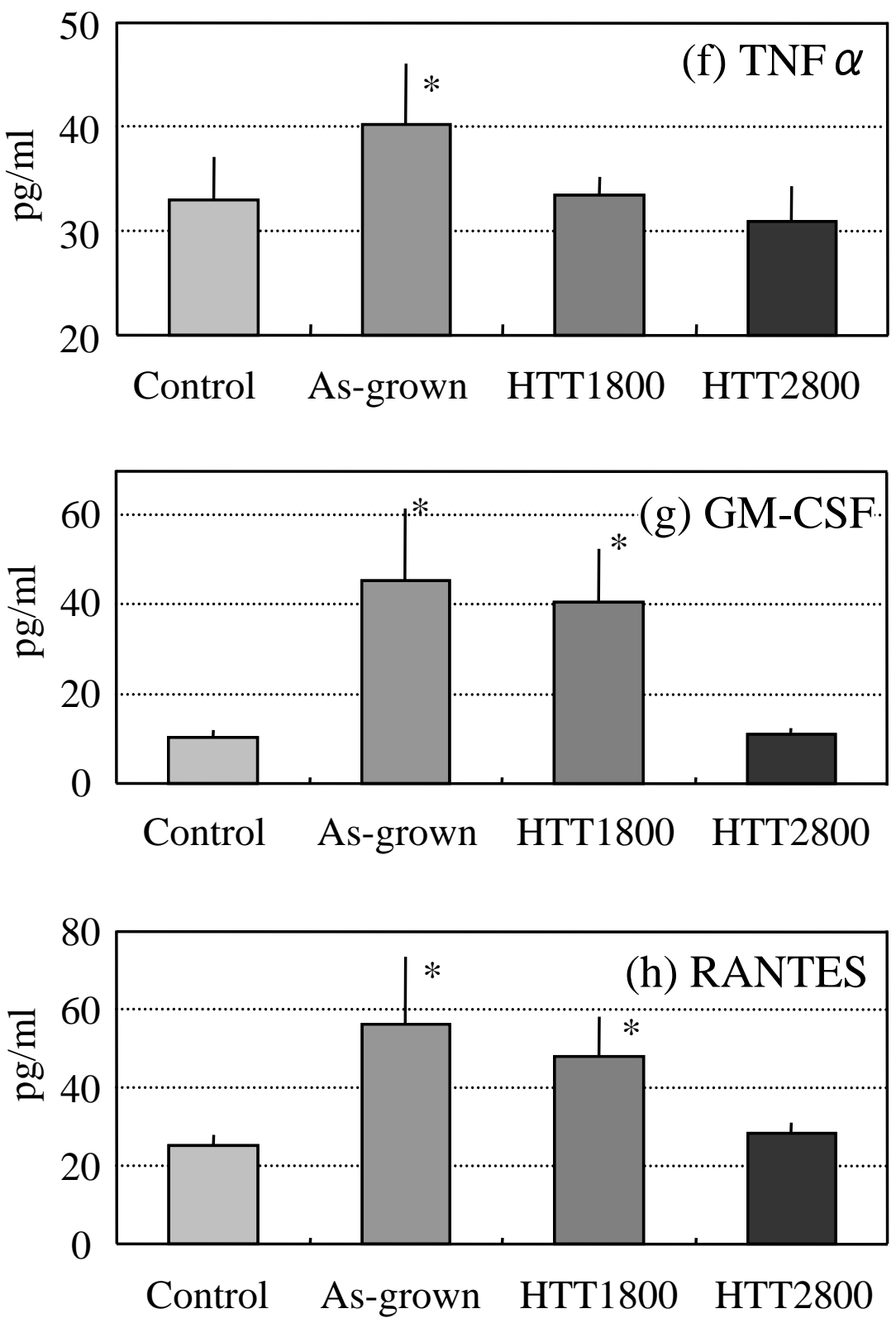

Figure S4. Time-dependent changes in (a) IL-2, (b) IL-3, (c) IL-5, (d) IL-9 (e) IL12, (f) TNF $\alpha$, (g) GM-CSF and (h) RANTES for the subcutaneously MWNTsimplanted mice, respectively. Asterisks indicate statically significant difference (P $<0.05$ ) versus control. 